\title{
Small Bowel Obstruction due to a Giant Meckel's Diverticulum
}

\author{
Andreas Minh Luu ${ }^{\mathrm{a}} \quad$ Kirsten Meurer $^{\mathrm{a}}$ Torsten Herzog ${ }^{\mathrm{a}} \quad$ Waldemar Uhla $^{\mathrm{a}} \quad$ Andrea Tannapfel $^{\mathrm{b}}$ \\ Chris Braumann ${ }^{a}$
}

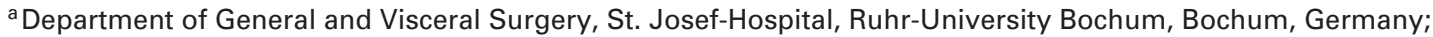

${ }^{b}$ Institute of Pathology, Ruhr-University Bochum, Bochum, Germany

\section{Keywords}

Giant Meckel's diverticulum - Small bowel obstruction . Ileus - Acute abdomen

\section{Summary}

Background: Meckel's diverticulum is the most common congenital anomaly of the gastrointestinal tract, with an average length of $3 \mathrm{~cm}$. Complications occur in $6.4 \%$ and most commonly include inflammation and gastrointestinal bleeding. Preoperative diagnosis is demanding and achieved in 4\%. Case Report: A 34-year-old otherwise healthy patient presented with an acute abdomen due to small bowel obstruction. Computed tomography scan could not identify the underlying cause. Emergency laparotomy was performed, and a torqued giant Meckel's diverticulum measuring $17 \mathrm{~cm}$ was found as the underlying cause for the small bowel obstruction. Resection of the affected ileum segment and ileo-ileal reconstruction were performed. The postoperative course was uneventful. Conclusion: In extremely rare cases, small bowel obstruction in an otherwise healthy patient might be caused by torsion of a symptomatic giant Meckel's diverticulum.

(c) 2016 S. Karger GmbH, Freiburg

\section{Introduction}

Meckel's diverticulum is the most common congenital anomaly of the gastrointestinal tract deriving from an incomplete obliteration of the vitelline duct [1]. It is usually asymptomatic and is often found incidentally during surgery. Acute inflammation mimicking acute appendicitis and lower gastrointestinal bleeding are the most common complications of a symptomatic Meckel's diverticulum
[2]. Gangrene secondary to axial torsion of a giant Meckel's diverticulum is seldom [3-5]. Tertiary small bowel obstruction belongs to the rarest but most serious complications [6-9].

We present a rare case of small bowel obstruction due to axial torsion of a giant Meckel's diverticulum.

\section{Case Report}

A 34-year-old patient presented to our hospital complaining about increasing generalized abdominal pain, nausea, and vomiting for 5 days. Bowel movements were normal. Both medical and surgical history were unremarkable.

Physical examination revealed diffuse abdominal tenderness on palpation with muscular defense.

Ultrasound demonstrated small bowel obstruction with dilated small bowel loops and non-propulsive peristalsis. Abdominal X-ray ruled out pneumoperitoneum, and computed tomography (CT) scan showed small bowel obstruction in the right lower abdominal quadrant (fig. 1, 2). Laboratory investigations showed: white blood cell count $11 \times 10^{9} / 1$, C-reactive protein $305 \mathrm{mg} / 1(<5)$, and creatinine $2.27 \mathrm{mg} / \mathrm{dl}(0.5-1)$.

Acute abdomen with small bowel obstruction of unknown etiology indicated emergency laparotomy.

A torqued and gangrenous giant Meckel's diverticulum measuring $17 \mathrm{~cm}$ in length was identified as the cause for the small bowel obstruction (fig. 3). After incision of the small intestine, 41 of small intestine fluid were sucked. Resection of the affected ileum segment $40 \mathrm{~cm}$ orally to the ileocecal valve and ileo-ileostomy were performed. The postoperative course was uneventful. The patient was discharged at postoperative day 10 .

Pathohistological findings demonstrated a severe inflammation of a Meckel's diverticulum with transmural necroses involving the adjacent small bowel wall (fig. 4).

\section{Discussion}

Meckel's diverticulum is a true diverticulum which was first described by Johann Friedrich Meckel in 1809 [10]. It is typically located up to $100 \mathrm{~cm}$ away from the ileocecal valve and occurs in $2 \%$ of the general population with an average size of $3 \mathrm{~cm}$. Giant

\section{KARGER}

(c) 2016 S. Karger GmbH, Freiburg

Fax +497614520714 


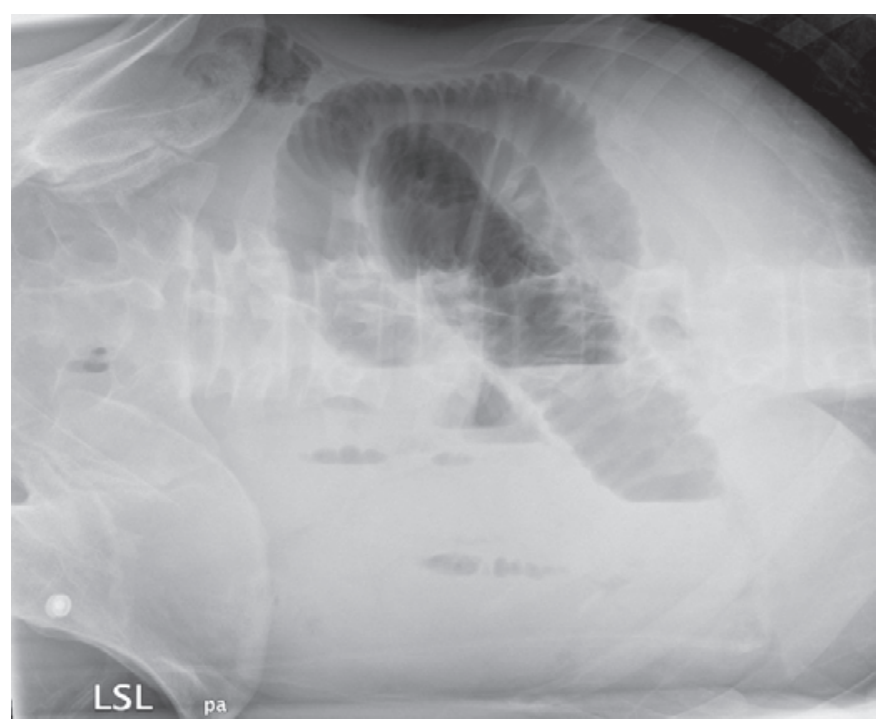

Fig. 1. Abdominal $\mathrm{X}$-ray demonstrating ileus.

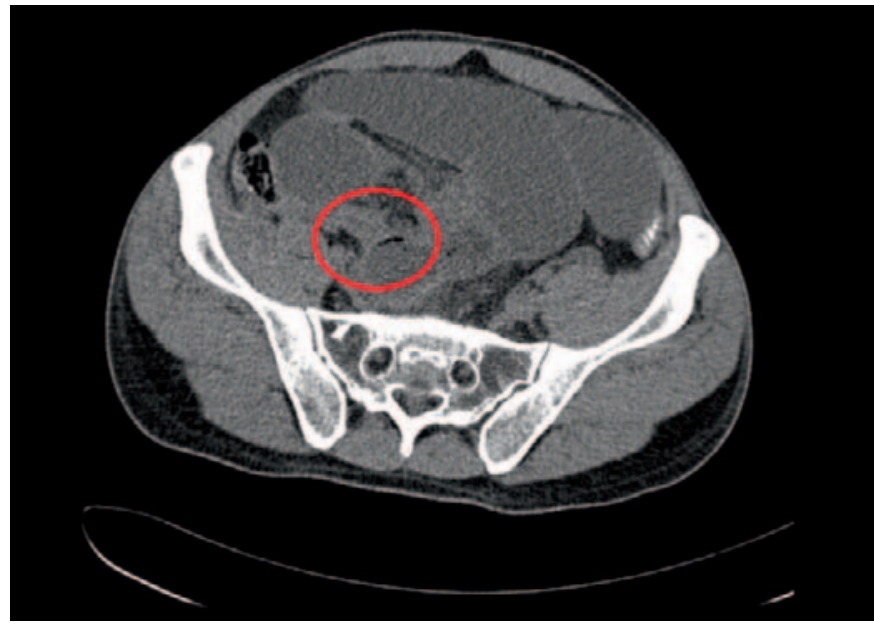

Fig. 2. CT scan depicting small bowel obstruction.

Meckel's diverticula are defined as diverticula measuring more than $5 \mathrm{~cm}$ [11]. Complications of this anomaly comprise inflammation, obstruction, and bleeding $[1,2,12]$. Small bowel obstruction due to torsion of a giant Meckel's diverticulum is scarce $[8,9]$. The lifetime risk for a symptomatic Meckel's diverticulum has been estimated to be as high as $6.4 \%$ [13]. Preoperative identification of a Meckel's diverticulum as the cause for an acute abdomen is achieved in $4 \%$ [14]. The most common suspected diagnosis in a patient with symptomatic Meckel's diverticulum is acute appendicitis [2]. While ultrasound and CT scan are frequent diagnostic tools, final diagnosis is often achieved during surgery. Ultrasound can be challenging due to bowel gas, and differentiation between small bowel loops and a Meckel's diverticulum is nearly impossible on CT scan [1].

In our extremely rare case, axial torsion of a giant Meckel's diverticulum led to gangrenous small bowel obstruction with acute kidney failure. A surgical approach was pursued to identify the underlying cause of the acute abdomen.

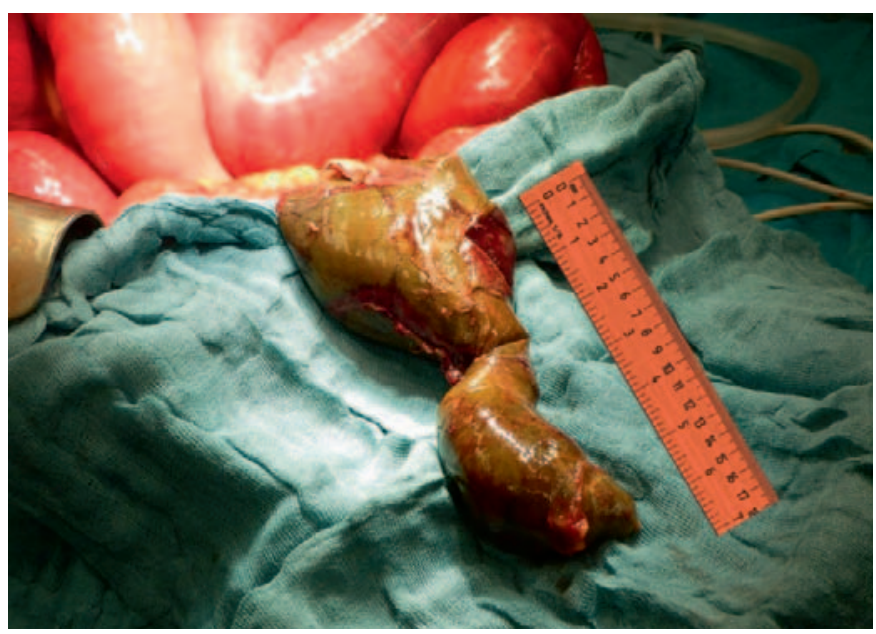

Fig. 3. Specimen of the giant Meckel's diverticulum measuring $17 \mathrm{~cm}$ in length. A virtual ruler is placed next to the diverticulum.

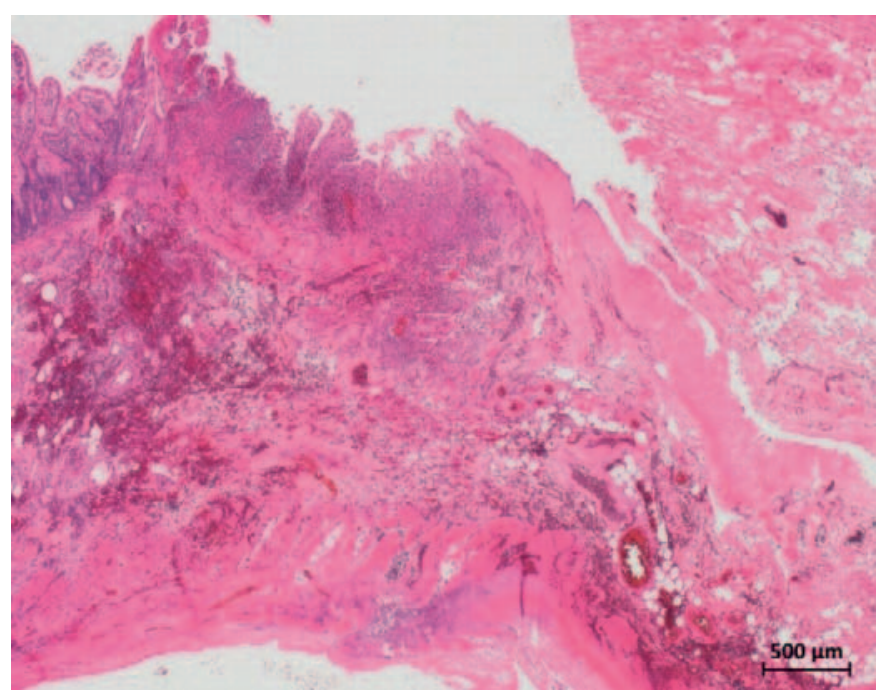

Fig. 4. Pathohistological finding of the gangrenous giant Meckel's diverticulum.

Symptomatic giant Meckel's diverticulum is a rare but important differential diagnosis in a patient with small bowel obstruction without surgical history.

\section{Conclusion}

Torsion of a giant Meckel's diverticulum is a rare cause of small bowel obstruction and requires emergency surgery. Preoperative diagnosis is a challenge for the surgeon, whereas surgical therapy is quite feasible. Symptomatic Meckel's diverticulum causing an acute abdomen is an important differential diagnosis in patients without surgical history.

\section{Disclosure Statement}

The authors declare no conflict of interest. 


\section{References}

1 Yahchouchy EK, Marano AF, Etienne JC, Fingerhut AL: Meckel's diverticulum. J Am Coll Surg 2001;192: 658-662.

2 Loh JC, Kruschewski M, Buhr HJ, Lehmann KS: Safety of resection of symptomatic and asymptomatic Meckel's diverticulum and literature review (Article in German). Zentralbl Chir 2014;139:452-459.

3 Kirmizi S, Kirmizi DA, Karagul R, Tolan K: Giant Meckel's diverticulum torsion that mimics adnexal pathology. Int J Surg Case Rep 2016;24:139-141.

4 Kiyak G, Ergul E, Sarikaya SM, Kusdemir A: Axial torsion and gangrene of a giant Meckel's diverticulum mimicking acute appendicitis. J Pak Med Assoc 2009; 59:408-409.

5 Ong MW, Tan KK, Sim R: Laparoscopic resection of a huge gangrenous Meckel's diverticulum in an adult. Singapore Med J 2013;54:e83-84.
Akbulut S, Yagmur Y: Giant Meckel's diverticulum: an exceptional cause of intestinal obstruction. World J Gastrointest Surg 2014;6:47-50.

7 Koudelka J, Kralova M, Preis J: Giant Meckel's diverticulum. J Pediatr Surg 1992;27:1589-1590.

8 Ren B, Jia X, Meng X, Li L: Intestinal obstruction due to axial torsion of a giant Meckel's diverticulum: a case report. Int J Colorectal Dis 2015;30:1133-1134.

9 Caiazzo P, Albano M, Del Vecchio G, Calbi F, Loffredo A, Pastore M, De Martino C, Di Lascio P, Tramutoli PR: Intestinal obstruction by giant Meckel's diverticulum. Case report. G Chir 2011;32:491-494.

10 Meckel J: Ueber die Divertikel am Darmkanal. Arch Physiol 1809;9:421-453.

11 Mackey WC, Dineen P: A fifty year experience with Meckel's diverticulum. Surg Gynecol Obstet 1983;156: 56-64.
Kusumoto H, Yoshida M, Takahashi I, Anai H, Maehara Y, Sugimachi K: Complications and diagnosis of Meckel's diverticulum in 776 patients. Am J Surg 1992; 164:382-383.

13 Cullen JJ, Kelly KA, Moir CR, Hodge DO, Zinsmeister AR, Melton LJ 3rd: Surgical management of Meckel's diverticulum. An epidemiologic, population-based study. Ann Surg 1994;220:564-568; discussion 568569.

14 Ludtke FE, Mende V, Kohler H, Lepsien G: Incidence and frequency or complications and management of Meckel's diverticulum. Surg Gynecol Obstet 1989;169: 537-542. 